\title{
Experimental Study on Multi-ball Training Method in College Tennis Elective Course Teaching
}

\author{
Cheng $\mathrm{Luo}^{1, \mathrm{a}}$, Yuxiang $\mathrm{Wu}^{2, \mathrm{~b} \text {, * }}$ \\ ${ }^{1}$ Wuchang Institute of Technology, Wuhan 430065, China; \\ 2 School of Physical Education, Jianghan University, Wuhan 430056, China; \\ a609410498@qq.com, b408328331@qq.com \\ *Author for correspondence: 408328331@qq.com
}

Keywords: tennis; multi-ball; teaching; elective course; training method

\begin{abstract}
For most college students, in the beginning of the tennis course, majority of them did not have chance to play tennis, not only the basic skills of tennis is relatively poor, but also lack of awareness of the tennis movement. Therefore, in the actual tennis teaching, there are many difficulties when many college students in the first contact with the tennis training. Besides, college tennis training time and space is limited, using simple sparring way often affected the tennis training efficiency and had poor training results. On the contrary multi-ball tennis training method developed a new effective way of tennis teaching in colleges and universities. Through literature review, logical analysis and other research methods, this paper analyzes the role of the different stages of the training method in tennis teaching, and expounds how to use the multi ball training method and the effect of the use of multi ball training method in tennis teaching. The experimental results show that the multi-ball training method can improve students' learning interest, and it has a good effect on mastering the basic technology of tennis, improving the ability of actual combat.
\end{abstract}

\section{Introduction}

Tennis is a sport of entertainment and enjoyment, it can not only provide to the participants of the entertainment and self satisfaction, but also to provide the audience with the enjoyment of art. With $\mathrm{Li} \mathrm{Na}$ and a number of Chinese tennis players frequently appeared in the world's top events, tennis began to become popular in college students, this is full of youthful vitality of the group.

However, after all, tennis is a professional competitive sport, which has a certain technical threshold for the participants. Tennis education in China started late, the vast majority of college students before have no contact with the tennis, not to mention tennis sparring, and most of them are the only child, from small hand foot and lack of enough physical exercise and physical quality condition is poor, athletic ability and body coordination are lacking. Their only advantage is that they have a positive attitude, a strong desire for knowledge and interest.

According to the investigation on the surrounding colleges and exchanges that, many schools for college tennis courses are still at the exploratory stage of the primary curriculum, tennis teaching books in the classroom content, practicality is not high, cramming teaching is lack of pertinence and professional sports teachers, too much emphasis on the teaching syllabus completion speed, ignoring the congenital conditions of college students, students in a very limited time to glance over things hurriedly in the study and practice of the technology, and ultimately tend to appear less effect, in addition, PE teachers in tennis teaching points and skills for tennis training in no repetition technology demonstration is very good, students in the batting practice in unknown so, the failure rate is very high, and the ball back to pick up the ball most of the time only simple machines, it is difficult to form a standard and correct technical movement, finally, this practice will only make students lose interest in tennis, and even give up resistance. Therefore, how to lead students into the palace, and gradually into the professional training and the actual combat, this is a problem worthy of deep thinking and exploration. 


\section{Method}

Through literature review and expert interview, the basic background of the research is to study the key variables of the multi ball training method by comparing the research method and the statistical method. Among them, the experimental group is: the teacher in the tennis teaching process, using the multi ball training method. While the control group is: the teaching process, through the general routine teaching method is now widely used to practice, that is, each class of the classroom tasks and skills learning requirements, technical action demonstration and explanation, and then organize the students to practice, and to correct the wrong action.

In tennis teaching in ordinary colleges and universities, in the implementation of multi ball training method by experimental class and control class college tennis technology learning effect, the experimental method, several key factors of tennis teaching for verification and research, with examples and data illustrate a variety of multi balls training method with respect to the single conventional multi ball training method, of College Students tennis learning effect is more effective, and discuss some of the details.

In this experiment, the teacher in front of the net net distance of six meters, with the racket toss, 30 balls in a group. A student of continuous exercise forehand and backhand every group. To ensure the experiment under the same conditions, to avoid the interference of irrelevant factors. The whole experimental period was 16 weeks. In the process of each factor, 50 students were randomly selected as the sample. In the process of the experiment, the factors of field equipment and other factors are same. To ensure that the test of fairness and justice, the test is not a teacher training. For the Wuchang Institute of technology and teaching and research section, with two teachers of tennis teaching experience.

Table 1. Statistics of the physical quality of the experimental and control group

\begin{tabular}{llccc}
\hline & & M & Std.D & Std.E Mean \\
\hline Height $(\mathrm{cm})$ & $\begin{array}{l}\text { Control group } \\
\text { Experimental } \\
\text { group } \\
\text { Control group }\end{array}$ & 171.28 & 2.977 & 0.432 \\
Weight $(\mathrm{kg})$ & $\begin{array}{l}\text { Experimental } \\
\text { group }\end{array}$ & 71.30 & 2.635 & 0.465 \\
& 73.67 & 5.690 & 1.126 \\
\hline
\end{tabular}

From the data in Table, the test statistics of the $\mathrm{F}$ test for the control group and the experimental group were $\mathrm{F}_{\text {Height }}=0.006, \mathrm{~F}_{\text {Weight }}=0.009$, respectively. The concomitant probability were $\mathrm{P}_{\text {Height }}=0.962, \mathrm{P}_{\text {Weight }}=0.932$. Therefore $\mathrm{F}$ test was accepted the assumption that in control group and the experimental group there were no significant differences in height and weight variance.

\section{Results}

In the research of multi-ball training method, the control class only take the ball directly, and the experimental group had three ways of training: direct feed (DF), bounce feed (BF) and combination of long and short shot (CLSS). There are a variety of ways of the multi ball training in tennis, in order to compare the different way of college tennis ball to promote the role of technology, the superposition method is used for testing, statistics of 50 balls success rate (one ball per person) by forehand or backhand were shown in figure 1and figure 2. 


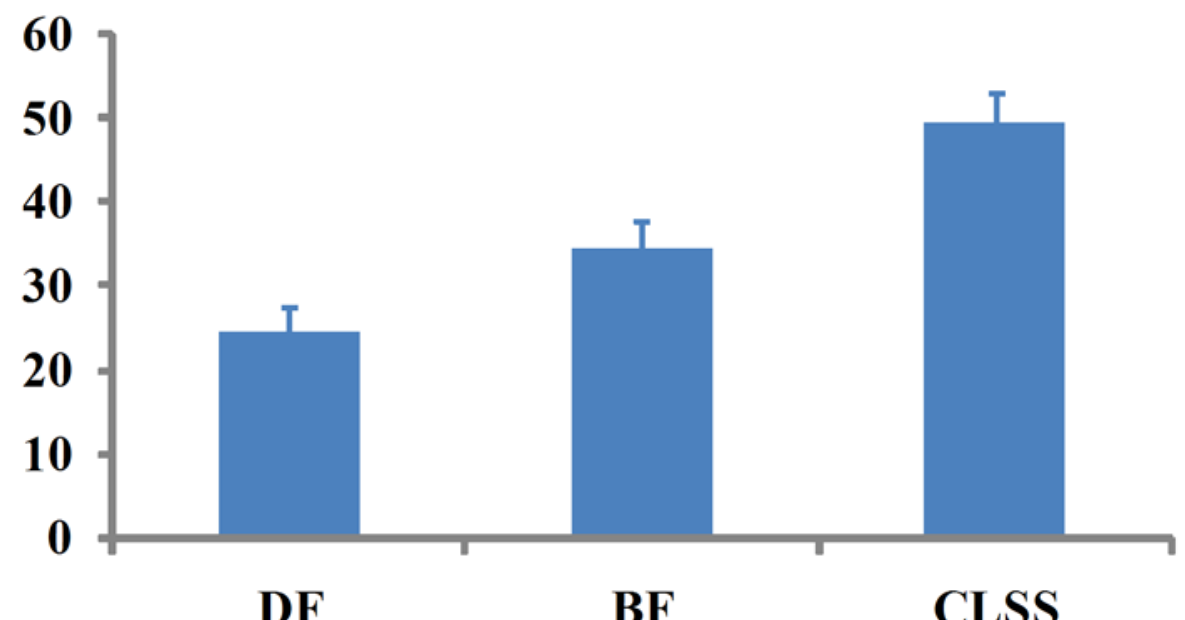

Figure 1. Success rate of multi-ball training method by forehand.

The results of figure 1 and figure 2 showed that different ways of training courses for the ball are effective and necessary. Single ball training is helpful to improve college students in tennis technique, but the single ball training method is impossible to solve all problems. multi-ball training method play a decisive role in the college tennis. From the experimental group and control group in the technical statistics, we see that with the increase of training course to give the ball way, represented by forehand and backhand tennis technical indicators showed a trend of rising.

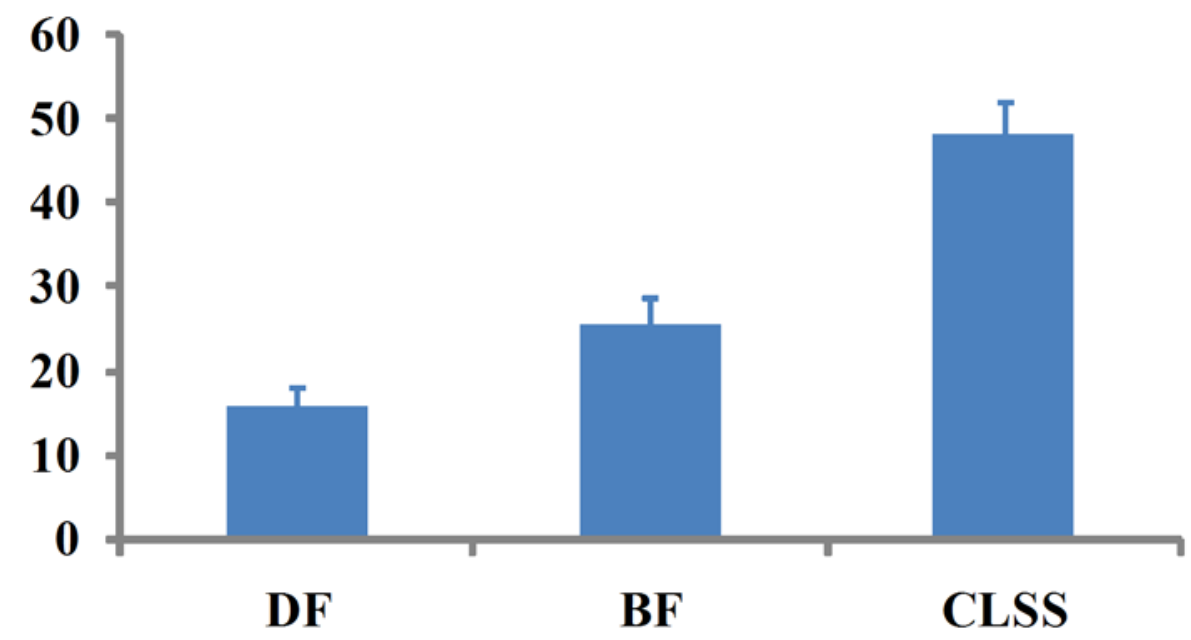

Figure 2. Success rate of multi-ball training method by backhand.

In the control group of training named DF, forehand of the control training subjects have a success rate of $24.5 \%$, backhand have a success rate of $15.7 \%$, when the bounce feed (BF) way added to give the ball in the training course, (teachers) picked up the ball to the ball, tennis throw on the ground first, from the ground bounce tennis court to practitioners (undergraduate), in which students can practice and get into the groove of the teacher to hit the ball, forehand success rate increased to $34.6 \%$, backhand success rate increased to $25.6 \%$. On this basis, combination of long and short shot (CLSS) can effectively increase the dimensional feeling of college students and the strength of the ball, the angle of the anticipation of the route and perception and movement, also can effectively improve the success rate of stroke, the forehand success rate increased to $49.3 \%$, backhand success rate increased to $48.2 \%$. The success rate of training by CLSS is better than $\mathrm{DF}(\mathrm{P}<0.05)$ and $\mathrm{BF}(\mathrm{P}<0.05)$.

\section{Discussion and Conclusion}

In tennis training, many balls training proportion is increasing, and get great use. In the provincial team, many balls training time accounted for $20 \%$ of the total training time to $25 \%$. In amateur sports school tennis training, many balls training for three hours a day training of about 40 minutes. The 
training of multi ball for different levels of college students' improvement and improvement of the tennis movement is very good, which is the basis of the multiple practice, from the macro point of view, from a variety of training mode to consolidate and practice tennis technology, can strengthen the corresponding brain area of the stimulation, and from microscopic, this is a frequent and repeated stimulation, which is the basis of brain learning and memory, and on the other hand, the brain to technical action of memory and understanding, and will strengthen and speed up the regulation of muscle, so as to speed up the ball to make judgments and reflect.

This research shows that the general college students in tennis class, a variety of integrated training needs to be combined with each other, in order to achieve a good training effect. In the tennis ball training, the way of giving the ball should be valued. The teacher's position on the college students is closely related to the position of the ball, the ball frequency, the rhythm and the ball strength are also affected. Thus, in the course of tennis ball training, the teachers should take different ways according to the different levels of students. This inspires us, for the tennis teachers in Colleges and universities in tennis teaching, we need to pay attention to the basic situation of college students, the college students should be regarded as the main body of education and teaching. In the actual situation of college students, at least according to the students' learning level and need to specify teaching plan. To strengthen exchanges with students, and to understand their confusion and needs, establish a good teaching atmosphere and teacher-student relationship, through practical teaching arrangements and emotional counseling to consolidate college students' tennis learning enthusiasm, to find a suitable for college students in tennis teaching program, to abandon the unified strength, uniform difficulty, and effectively improve the efficiency of tennis and tennis teaching level.

\section{References}

[1]. O Girard, G Lattier, J-P Micallef, et al. Changes in exercise characteristics, maximal voluntary contraction, and explosive strength during prolonged tennis playing. British Journal of Sports Medicine. Vol. 40(2006) p. 521-526.

[2]. Machar Reid, Knut Schneiker, Strength and conditioning in tennis: Current research and practice. Journal of Science and Medicine in Sport. Vol. 11(2008), No. 3, p. 248-256.

[3]. Barber-Westin, Sue D; Hermeto, Alex A; Noyes, Frank R, et al. A Six-Week Neuromuscular Training Program for Competitive Junior Tennis Players. Journal of Strength \& Conditioning Research. Vol. 24(2010) No. 9, p. 2372-2382.

[4]. Nicola A. Maffiuletti, Jacopo Bramanti, Marc Jubeau, et al. Feasibility and Efficacy of Progressive Electrostimulation Strength Training for Competitive Tennis Players. Journal of Strength \& Conditioning Research. Vol. 23(2009) No. 2, p. 677-682.

[5]. Emilio J. Martínez-López, Alberto Grao-Cruces, José E. Moral-García, et al. Intervention for Spanish Overweight Teenagers in Physical Education Lessons. Journal of Sports Science \& Medicine. Vol. 11(2012) No. 2, p. 312-321.

[6]. Nicola A. Maffiuletti, Physiological and methodological considerations for the use of neuromuscular electrical stimulation. European Journal of Applied Physiology. Vol. 110(2010) No. 2, p. 223-234

[7]. Kovacs, Mark S,Roetert, E Paul, Ellenbecker, Todd S, et al. Efficient Deceleration: The Forgotten Factor in Tennis-Specific Training. Strength \& Conditioning Journal. Vol. 30(2008) No. 6, p. 58-69.

[8]. MS Kovacs, Applied physiology of tennis performance. British Journal of Sports Medicine. Vol. 40(2006) p. 381-386. 